\title{
Critérios de justiça e programas de renda mínina
}

\author{
Simone Diniz \\ Instituto Paulista de Ensino (FIPEN) \\ Pontifícia Universidade Católica de São Paulo (PUCSP)
}

\section{Critérios de justiça e programas de renda mínina}

Resumo: Este artigo tem por objetivo analisar três programas de renda mínima, transformados em lei de âmbito federal. O primeiro, instituído por lei, durante a presidência de Fernando Henrique Cardoso, concedia apoio financeiro aos municípios para criarem programas de garantia de renda mínima associados a ações socioeducativas. O segundo programa analisado é o Bolsa Família, aprovado por lei e instituído na gestão do governo Lula. O terceiro programa, de autoria do senador Suplicy, é aquele que institui uma renda básica de cidadania. Esta análise insere-se em um debate mais amplo relacionado à defesa de uma renda incondicional, como forma de superação do Estado de bem-estar social. O argumento central é que no Brasil, mesmo na gestão de Lula, têm prevalecido políticas de cunho focalizado em detrimento das universalizantes.

Palavras-chave: renda mínima universal, Bolsa Família, política social, Estado de bem-estar social.

\section{Criteria of Fairness and Minimum Income Programs}

Abstract: The purpose of this article is to analyze three minimum income programs, transformed into law on the federal level. The first, created during the Fernando Henrique Cardoso Administration, offers financial support to municipalities by creating programs to guarantee minimum income associated to social-educational activities. The second program is the Family Grant program instituted during the Lula government. The third program, drafted by Senator Eduardo Suplicy, institutes a basic citizens' income. The analysis is inserted in a broader debate related to defense of unconditional income, as a form of overcoming the social welfare state. The central argument is that Brazil, even during the Lula government, has emphasized focused policies at the cost of universal ones.

Key words: universal minimum income, Family Grant, social policy, social welfare state. 


\section{Introdução}

No Brasil, o debate em busca de uma forma de combate à pobreza não é recente, mas é só a partir do início dos anos 1990 que uma forma específica de política social - a garantia de uma renda mínima ganha destaque e apoiadores de diferentes correntes ideológicas. O tema adquiriu maior dimensão a partir da implantação de alguns programas localizados no Distrito Federal, em Campinas e em Santo André, por exemplo, entre tantos outros casos.

A implantação de programas dessa natureza não é recente. Na Europa Ocidental, na Dinamarca, o programa foi implantado em 1933, na Inglaterra em 1948, na Alemanha em 1961, na Holanda em 1963, na Bélgica em 1974, na Irlanda em 1977, em Luxemburgo em 1986 e na França em 1988 (LAVINAS; VARSANO, 1998).

De acordo esses autores (1998, p. 51), embora existam algumas particularidades que os diferenciam, há um núcleo comum nos programas desses países: a) destinam-se a todos aqueles que se encontram em situação de necessidade decorrente de insuficiência de renda - respeitam, portanto, um princípio de universalidade; b) o benefício é atribuído com base em uma demanda feita pelo próprio interessado; c) implicam no respeito a certas prerrogativas e, em alguns casos, a contrapartidas; d) o benefício tem seu valor modulado pelo montante das demais prestações sociais e pela renda individual ou familiar do requerente.

Ainda, segundo os autores citados, três posições estruturam o debate quanto à adoção desse tipo de programa. Uma, denominada de incondicionalidade forte, propõe uma renda de subsistência para todos, sem distinção nem pressupostos condicionantes; outra, chamada de incondicionalidade débil, prevê um imposto de renda negativo apenas para aqueles que não dispõem do mínimo para viver dignamente. Uma terceira, denominada de workfare, condiciona a concessão do benefício ao desenvolvimento de atividade laboral de todos aqueles que estejam aptos ao trabalho, ou seja, estabelece contrapartidas para o acesso ao programa.

O objetivo deste artigo é apresentar os argumentos de um dos defensores da incondicionalidade forte, Philippe Van Parijs, filósofo e professor na Universidade Católica de Louvain, e, em seguida, analisar o conteúdo dos projetos apresentados pelo deputado Nelson Marchezan (PPR-RS), durante o primeiro mandato de Fernando Henrique Cardoso (FHC), pelo senador Eduardo Suplicy e pelo presidente Lula, ambos já na gestão deste último, e transformados, respectivamente, nas Leis 9.533/97, 10.835/ 04 e 10.836/04 (BRASIL, 2006a). O argumento central é que, no Brasil, mesmo na gestão de Lula, têm prevalecido políticas de cunho focalizado em detri- mento de ações universalizantes. Na primeira seção deste texto, é apresentado o debate sobre a necessidade da adoção de políticas de renda de forma incondicional. Na segunda, é feito um breve histórico das políticas sociais no Brasil, de forma a introduzir a análise dos programas de renda mínima expostos na terceira seção. Na última seção, a modo de conclusão, são apresentados os principais dilemas a serem enfrentados na adoção desses programas.

\section{Adoção de renda incondicional}

As políticas sociais ou o 'Estado de bem-estar social' podem ser entendidos como "[...] um regime específico de transferências sociais, de base fiscal, cujo objetivo é promover o bem-estar dos indivíduos mediante uma redistribuição de renda e da riqueza (ativos) comprometida com a idéia de justiça" (LAVINAS, 2000, p. 1).

A introdução de uma renda incondicional é vista por Van Parijs (1994, p. 69) como uma política social que supera o "Estado de bem-estar social" tradicional. Não se trata de um desmantelamento do conjunto de medidas e intervenções sociais que caracterizam e/ou caracterizaram os modelos de welfare state, mas sim, de uma nova modalidade de intervenção estatal, assentada em outros padrões éticos que não aqueles que orientaram a implantação dos welfare states tradicionais.

Os tipos de welfare hoje existentes têm por base ora um modelo denominado de (1) bismarkiano, que consiste em um sistema de seguros sociais, de caráter obrigatório, que funciona ex-post; ora um de tipo (2) beveridgeano que recorre à noção de solidariedade e assenta-se em transferências ex-ante; ou num modelo (3) paineano, sustentado por uma concepção de eqüidade que se materializa na concessão de uma renda básica incondicional (VAN PARIJS, 1995).

Para justificar a sua concepção de justiça que norteará sua defesa da adoção da renda básica incondicional, Van Parijs recapitula os argumentos apresentados pelos filósofos-economistas da metade do século 19 com o objetivo de demonstrar como a concepção utilitarista teve que gradualmente se reformular para dar conta de dizer o que constitui uma distribuição justa dos níveis de vida, abrindo assim, em seu cerne, um espaço essencial à noção de liberdade.

No que consiste esse argumento? O método utilitarista observa as escolhas feitas pelos indivíduos. Assim, a escolha que gerar maior utilidade é a mais justa. Agindo dessa forma estaríamos comparando as preferências individuais entre si. Na concepção utilitarista, em matéria de distribuição, segundo Van Parijs (1997, p.141), "tratava-se de maximizar o bem-estar coletivo, definido como a soma dos níveis de bem-estar dos indivíduos que compunham a soci- 
edade considerada. A maneira como os níveis de vida são distribuídos não importa como tal. Importa somente seu impacto sobre esse agregado que é o bemestar coletivo".

Como argumenta este autor (1997, p. 30) alguns problemas decorrem desta sistemática. "Quem são os indivíduos cuja utilidade deve ser considerada quando comparamos a soma das utilidades correspondentes às diversas opções? A dimensão populacional deve ser tomada como variável? Qual é a natureza das 'utilidades' individuais voltadas para maximizar a soma?'.

Com o decorrer do tempo, tornou-se evidente a impossibilidade de comparação interpessoal das utilidades. Em resposta, a tradição utilitarista passou a recorrer à avaliação de estados possíveis da economia segundo um critério de eficiência (ou eficácia) definido por Van Parijs (1997, p. 142) como "um estado da economia é Pareto-Ótimo se não existe nenhum outro estado possível no qual ao menos um agente desfrute de um nível de bem-estar superior enquanto o bem-estar de nenhum outro agente é nele menor".

A utilização de um conceito ordinal também apresenta deficiências, pois só serve como escolha entre A e B, se houver unanimidade na preferência entre A ou B. O impulso necessário para resolver esta questão veio com a publicação do teorema de Arrow, que

[...] através do teorema da impossibilidade, demonstra que o utilitarismo ordinalista se encontra preso em um dilema entre, de um lado, a indeterminação do critério de Pareto e, de outro, a possibilidade de irracionalidade coletiva inerente a qualquer procedimento de agregação puramente ordinal das preferências individuais que se afaste do simples critério de Pareto para romper com a sua indeterminação (VAN PARIJS, 1997, p.143).

Este teorema, segundo o autor, também induziu a um questionamento do próprio utilitarismo, cuja implicação é a de que o bem-estar dos indivíduos deixa de constituir a única informação pertinente para guiar as escolhas coletivas. A exigência de eficiência, por mais fraca que seja a sua definição, já constitui um julgamento de valor. Van Parijs defenderá a adoção de considerações distributivistas no lugar da exigência de eficiência, pois para ele, é da preocupação com questões distributivas que surge o interesse pelas questões de igualdade.

Pelo princípio da igualdade todos os indivíduos devem receber tratamento igual. Nele está implícita a noção de que todos são iguais e têm, portanto, direito de receberem os mesmos recursos.

Já o princípio da eqüidade assume que os indivíduos são diferentes entre si e, portanto, merecem um tratamento diferenciado, que elimine ou reduza a desigualdade. É o princípio da eqüidade que está presente na teoria da Rawls ao explicitar que o trata- mento desigual é justo quando beneficia o indivíduo mais necessitado.

A formulação do "princípio da diferença" de Rawls, de acordo com Van Parijs (1997, p. 146), tem por objetivo articular considerações de igualdade e eficiência, podendo, eventualmente, "justificar as fórmulas concretas de distribuição que diferem de um contexto a outro".

Uma Teoria da Justiça de Rawls (1993, p. 68) baseia-se em dois princípios: o primeiro estabelece um sistema igual de liberdade para todos:

[...] cada pessoa deve ter um direito igual ao mais extenso sistema de liberdades básicas que seja compatível com um sistema de liberdades idêntico para as outras; o segundo determina sob quais condições sociais essas liberdades devem ser distribuídas de forma a que, simultaneamente: a) se possa razoavelmente esperar que elas sejam em benefício de todos; b) decorram de posições e funções às quais todos têm acesso.

O "princípio da diferença” (VAN PARIJS, 1997, p. 147) vincula-se diretamente ao segundo princípio. Trata-se de maximizar as oportunidades de renda, poder, bem-estar, etc. dos mais desfavorecidos, pois, como afirma, desigualdades sociais e econômicas só são legítimas se contribuem para melhorar a sorte dos mais desfavorecidos.

Para Van Parijs, na seqüência, "o princípio foi formulado não em termos de utilidade ou de bem-estar, mas em termos do que Rawls denomina de "bens sociais primários", os quais são os meios que permitem a cada um perseguir a realização de sua concepção de boa vida. Esses "bens sociais" Rawls (2000, p. 228) divide em cinco grandes categorias:

1. direitos e liberdades fundamentais, que também constituem uma lista;

2. liberdade de movimento e de livre escolha de ocupação num contexto de oportunidades diversificadas;

3. poderes e prerrogativas de cargos e posições de responsabilidade nas instituições políticas e econômicas da estrutura básica;

4. renda e riqueza;

5. bases sociais do auto-respeito.

A posição libertariana, diferentemente das teorias utilitaristas e igualitárias, introduz um importante elemento: atribui à liberdade um lugar central, pois impõe restrições às manipulações dos níveis de vida em nome da eficiência, da igualdade, ou da articulação dessas duas - a eqüidade -, reconhecendo-a como um direito de propriedade individual. A ressalva de Van Parijs (1997, p. 152, 157) a este último aspecto diz respeito ao fato de que liberdade como direito não é suficiente 
para que se possa realizar aquilo que se concebe como "boa vida" (consumir e produzir o que se deseja e como se deseja). "É preciso ainda que eu tenha o poder ou a capacidade de fazer realizar o que desejo. Senão, de que vale ter o direito de sair de férias, por exemplo, se não tenho os meios para fazê-lo?"

Para o autor, os libertarianos expandem o domínio ao qual se aplica o primeiro princípio de Rawls, atribuindo a cada um liberdades fundamentais máximas, mas não deixam espaço para a aplicação do segundo princípio (que exige a igualdade eqüitativa de oportunidades e a maximização dos benefícios dos mais desfavorecidos) ou para qualquer outro princípio de justiça distributiva. Advoga Van Parijs (1997, p.157) que é necessário dar a todos a maior "liberdade real possível". Trata-se, segundo ele, de uma volta "[...] senão ao princípio de diferença de Rawls, ao menos a um princípio estreitamente aparentado, pois dar a todos a maior liberdade real possível significa maximizar a liberdade real daquele que menos tem, ou ainda abolir todas as desigualdades de liberdade real que não contribuam para aumentar a liberdade real daquele que, nesse aspecto, é o mais desfavorecido".

Em seguida, o autor afirma que há uma estreita relação entre a "liberdade real" e os "bens sociais primários" de que se trata "no princípio da diferença" de Rawls:

Liberdade real consiste em um nível de vida assegurado a cada indivíduo sob a forma incondicional. Como tal, o nível de vida leva em consideração apenas a dimensão 'renda' de Rawls, a liberdade real de consumir. A exigência de incondicionalidade, entretanto, integra o que constituía importância de cada uma das outras dimensões mencionadas por Rawls, ao mesmo tempo em que permite assegurar o nível de vida suficiente para realizar, para além da liberdade real de consumir, a liberdade real de trabalhar e de não trabalhar.

$\mathrm{O}$ "princípio da diferença” poderia ser a "justificação para o sistema de renda mínima garantida, pois no rol dos 'bens primários' estão as bases sociais do autorespeito" necessárias para dar à pessoa um sentido firme de seu próprio valor e a confiança em si necessária para a perseguição de seus fins. Para que isto ocorra é necessário que o benefício seja distribuído de uma maneira que não estigmatize os beneficiários e que essa distribuição se faça em particular, sem controle dos recursos e sem controle da vida privada. Tratar-se-ia de uma "renda concedida de modo incondicional a cada cidadão (ou residente permanente), quer tenha ou não emprego, quer pense ou não em ter um, qualquer que seja sua condição conjugal e qualquer que sejam os seus rendimentos provenientes de outras fontes" (VAN PARIJS, 1997, p. 177, 179).
A adoção de uma renda básica universal atenderia aos preceitos de uma sociedade justa, porque não dá lugar às chamadas "arbitrariedades morais" (circunstâncias que são produto da "loteria natural" - recursos materiais, talento, etc.). Um sistema institucional que concede, incondicionalmente, um benefício a todos os cidadãos, estaria respondendo adequadamente a princípios igualitários, ainda mais se levarmos em consideração que o que está em jogo é a subsistência das pessoas (GARGARELLA, 1995, p. 326).

Que a adoção de uma renda básica universal atende a princípios igualitários parece não haver dúvidas. No entanto, uma questão importante é a de como atender a princípios de justiça em sociedades pobres? Embora Van Parijs (1994) seja um fervoroso defensor da renda básica universal incondicional, ele não recomenda a introdução de uma renda básica a todas sociedades. Para ele, somente em sociedades que se livraram da fome, ou que podem fazê-lo sem violação à propriedade de si mesmo, é que vale a pena falar em renda básica.

Há pelo menos dois problemas a serem enfrentados no que diz respeito à adoção de uma renda básica universal em sociedades pobres: número excessivo de beneficiários e poucos recursos a serem distribuídos. Isto, segundo Gargarella (1995), introduz um problema político sério - o de como organizar um movimento social efetivo para poder distribuir parte dos benefícios dos privilegiados, considerando-se, é claro, o que pode ser feito em condições institucionais dadas.

\section{Políticas sociais no Brasil}

A maior parte das políticas sociais no Brasil assenta-se num modelo bismarckiano e foram institucionalizadas entre as décadas de 1930 e 1970. Entre os anos 1930 e 40, a legislação social tratava, quase que exclusivamente, de questões previdenciárias e trabalhistas, e tinha como objetivo, embora nem sempre tenha sido alcançado, assegurar proteção aos trabalhadores urbanos, tendo em vista os baixos valores das aposentadorias e pensões. As outras áreas englobadas sob o rótulo de política social (educação, saúde, assistência social e, por último, habitação) tomaram formas mais institucionalizadas entre 1945 e 1964 (DRAIBE, 1989).

O processo constituinte de 1988 acenou com a possibilidade de um novo modelo de política que privilegiasse medidas de justiça social. Durante o período da 'Nova República' cresceu o número de programas assistenciais sem base contributiva, particularmente os de distribuição gratuita de bens in natura à população pobre. Esboçaram-se os primeiros passos em caminho à descentralização, principalmente na área da saúde, e começava a tomar corpo o deba- 
te quanto à necessidade de garantir a todos os cidadãos uma renda mínima (DRAIBE, 1989).

A Constituição de 1988 também significou uma profunda alteração no programa previdenciário rural. Os trabalhadores rurais foram inseridos no plano de benefícios do Regime Geral de Previdência Social. Isto significou que o piso de benefícios para aposentadoria e pensões passou a ser de um salário mínimo, e as mulheres passaram a ter acesso a aposentadorias e pensões independentemente de o cônjuge já ser beneficiário ou não(SCHWARZER, 2000).

Passada a euforia da promulgação da nova Constituição, tratar-se-ia de regulamentar os novos benefícios, porém, desde meados da década de 1980, um novo debate começou a estruturar-se em torno da busca de soluções contra o fraco desempenho econômico, os desequilíbrios financeiros e o processo inflacionário. A base de sustentação dos antigos modelos de welfare state começava a ruir. Alterações no 'mundo do trabalho' (terceirização, mudanças tecnológicas, dispensa de trabalhadores, etc.) colocaram na 'ordem do dia' a necessidade de se repensar o modelo de políticas sociais ${ }^{1}$.

\section{Programas de renda mínima no Brasil}

A adoção de uma política de renda mínima no Brasil, de acordo com Ramos (1998), vem sendo justificada a partir de três argumentações. A primeira delas é que um programa desta natureza romperia com a prática amplamente disseminada na política brasileira, de intermediação, pelos políticos profissionais, dos benefícios sociais de caráter estatal. Um dos desdobramentos de uma renda mínima garantida seria uma contribuição às mudanças nas práticas políticas e à democracia, na medida em que a utilização pessoal ou partidária de recursos públicos deixaria de ser uma ferramenta de campanha eleitoral. Em segundo lugar, as pessoas que estão fora do mercado formal de trabalho passariam a ter acesso a, pelo menos, um benefício mínimo. Por fim, a renda mínima poderia se tornar um instrumento de distribuição de renda.

No Brasil, até a gestão do presidente Lula, não existia, ainda que formalmente, uma renda mínima garantida a todos os cidadãos. Em 1975, o regime de previdência social implantou uma renda mensal vitalícia a todos os idosos com mais de 70 anos e a indivíduos portadores de invalidez que não preenchessem os requisitos necessários para recebimento de aposentadoria ou pensão. $\mathrm{O}$ benefício correspondia a meio salário mínimo. Com a Constituição de 1988, o valor do benefício passou a ser de um salário mínimo.

Com a promulgação da Lei 8.742 de 1993 (BRASIL, 2006b), os beneficiários da renda mensal vitalícia saíram da legislação do âmbito da previdência social e passaram a ser regidos pela lei que dispõe sobre a organização da assistência social. Por esta legislação (art. $2^{\circ}$., cap. V), a renda mensal vitalícia corresponde à "garantia de um salário mínimo de benefício mensal à pessoa portadora de deficiência ou idoso que comprove não possuir meios de prover a pró-

pria manutenção ou de tê-la provida por sua família". Para ter acesso ao benefício o idoso deve ter mais de 70 anos e renda familiar mensal inferior à quarta parte do salário mínimo.

No início da década de 1990, o debate sobre a adoção de uma renda básica universal ganhou destaque devido à apresentação de um projeto de lei pelo senador Eduardo Suplicy.

O projeto do senador propunha a adoção de um programa de imposto de renda negativo, que beneficiaria todas as pessoas residentes no país e maiores de 25 anos que auferissem menos de 45 mil cruzeiros na época (em 1991, em torno de 45 dólares em 1998). O valor seria corrigido nos meses de maio e novembro de cada ano ou toda vez que a inflação acumulada atingisse $30 \%$. Anualmente, no mês de maio, além da correção dos valores nominais em função da inflação passada, haveria um acréscimo real, da mesma magnitude da variação do PIB por habitante do ano anterior. A complementação monetária para cada indivíduo não corresponderia à totalidade do mínimo estabelecido, mas apenas a 30\% da diferença entre o rendimento auferido e esse patamar mínimo. Uma pessoa sem renda receberia 13.500 (30\% de 45.000). Se uma pessoa recebesse 20.000 receberia mais $7.500(45.000-20.000=25.000 \mathrm{x}$ $30 \%$ ). Com isto toda pessoa se sentiria motivada a procurar emprego, pois sempre seria melhor estar ocupado (RAMOS, 1998, p. 25).

A proposta previa ainda a implantação gradual do programa, começando pelas pessoas com mais de 60 anos (em 1995) e finalizando em 2002, quando se atingiria todo o universo previsto, isto é, todos os indivíduos maiores de 25 anos. Os recursos do programa seriam originários da União e, paralelamente à sua implementação, deveriam ser desativados os programas e entidades associados à política social com- 
pensatória. A alocação dos recursos da União não poderia exceder a $3,5 \%$ do PIB. Este projeto tramitou durante longos anos no Congresso e não chegou a ser aprovado.

No início da primeira gestão de FHC, em 1995, o deputado Nelson Marchezan (na época filiado ao PPB) apresentou um projeto de lei instituindo um programa de renda mínima. A versão original do projeto previa a concessão de uma renda mensal no valor de $\mathrm{R} \$ 30$ às famílias com renda familiar que não excedesse a um salário mínimo, por filho ou dependente na faixa de 0 a 14 anos, estando os maiores de 7 anos freqüentando regularmente a escola.

O acesso ao benefício também estava condicionado à freqüência, por parte do membro responsável pela família, em cursos de treinamento e aperfeiçoamento para capacitação profissional, independentemente de estar desempregado, subempregado ou mesmo empregado, conforme o parágrafo único do artigo $3^{\circ}$. do Projeto de Lei 667/95².

Pelo teor do projeto, o financiamento de tal programa estaria a cargo da União $(70 \%)$ e dos municípios (os 30\% restantes). Os municípios interessados em implementar o programa deveriam encaminhar proposta ao Ministério da Educação com informações quanto ao número de famílias e de crianças a serem atendidas, acompanhado de estimativa de custo e de parecer do Conselho Municipal da Criança e do Adolescente. A vigência do programa seria de 10 anos, passando por uma avaliação anual. Por fim, a atualização do benefício seria feita sempre que fosse alterado o salário mínimo e teria como base o índice oficial da inflação.

O deputado Oswaldo Biolchi (PTB-RS), relator do projeto, introduziu algumas mudanças significativas na redação. $\mathrm{O}$ artigo $1^{\circ}$. do projeto dizia: "fica autorizado o Governo Federal a conceder apoio financeiro aos municípios que instituírem programa de renda mínima, que não disponham de recursos financeiros para financiar integralmente a sua implementação". O caráter apenas autorizado e, portanto, não obrigatório ficou claramente explicitado. $\mathrm{O}$ apoio do Governo Federal estava restrito aos municípios com receita tributária por habitante, incluídas as transferências constitucionais correntes, inferior à respectiva média estadual e com renda familiar por habitante inferior à renda média familiar por habitante do estado. $\mathrm{O}$ valor do apoio financeiro era de $50 \%$ do valor dos respectivos programas. O restante deveria ser financiado pelo município, isoladamente, ou com ajuda do Governo Estadual.

Teriam acesso ao benefício as famílias com renda familiar por membro/pessoa inferior a meio salário mínimo, com filhos ou dependentes até 14 anos, sendo que os maiores de 7 anos deveriam estar matriculados e freqüentando regularmente a escola.

A condicionalidade de participação do responsável a curso de capacitação foi retirada do projeto.
Esta versão abarcaria um número maior de famílias, porém, ao definir a renda familiar per capita, aumentou significativamente as exigências para que o município recebesse apoio federal. Não há dúvida de que esta proposta era muito mais favorável às diretrizes traçadas pelo Governo Federal. Aliás, o próprio autor da matéria, deputado Nelson Marchezan, afirmou que o presidente Fernando Henrique teve participação decisiva a partir da Casa Civil e com auxílio do sub-chefe parlamentar, Eduardo Graeff, na negociação do projeto junto ao órgão do Executivo ${ }^{3}$.

A tramitação do projeto, tanto na Câmara quanto no Senado, ocorreu sem maiores sobressaltos. Aúnica alteração significativa feita pelos senadores foi a introdução do Distrito Federal, ausente nas versões anteriores do projeto, dentre aqueles a serem beneficiados com o apoio financeiro da esfera federal. $\mathrm{O}$ projeto foi aprovado, transformando-se na Lei 9.533/ 97 (BRASIL, 2006a).

O projeto tinha o mérito de complementar a renda de segmentos extremamente necessitados da população, mas o fato de ser apenas autorizativo era um importante entrave à eficácia do combate à pobreza e à eliminação da marginalidade de segmentos menos favorecidos. Havia também a vantagem de ser o município a unidade responsável pela implementação do projeto, o que favorecia não só sua fiscalização, mas também a modelagem de um programa que atendia às características da população local. Mas havia também uma série de aspectos que poderiam inviabilizá-lo. O deputado Gerson Peres (PPB-PA) expressou certo ceticismo quanto à eficácia do projeto.

[...] tenho minhas dúvidas quanto à execução dessa lei, ante sua constitucionalidade, pois se trata de matéria cuja autorização preventiva tem de ser do Poder Executivo - ela é simplesmente autorizativa. Disse o deputado Marchezan que conversou com o Presidente e que S. Exa. deu sinal verde. Queira Deus que essa ação supra o vício da inconstitucionalidade ${ }^{4}$.

O aspecto "apenas autorizativo" do projeto também foi citado, no mesmo documento, pelo deputado Inocêncio Oliveira (PFL-PE), mas este de maneira deliberada disse que não discutiria este aspecto, apenas ressaltaria a importância da adoção de uma renda mínima para o estabelecimento de justiça social no país.

\section{1 O Bolsa Família do governo Lula}

Em janeiro de 2004, o presidente Lula sancionou o seu principal programa social - o Bolsa Família (PBF), criado pela Lei n. 10.836/04, a partir de uma medida provisória editada pelo Executivo. Essa lei unificou o Bolsa Escola (Lei n. 10.219, abril de 2001), 
o Programa Nacional de Acesso à Alimentação (Lei n. 10.689, de junho de 2003), o Bolsa Alimentação (Medida Provisória n. 2.206-1, de setembro de 2001), o Auxilio-Gás (Decreto 4.102, de janeiro de 2002) e o Cadastramento Único do Governo Federal. (Decreto n. 3.877, julho de 2001) $)^{5}$.

$\mathrm{O}$ PBF é destinado às famílias em situação de pobreza e extrema pobreza, caracterizadas pela renda familiar mensal per capita de até $\mathrm{R} \$ 120$ e R\$60, respectivamente.

Os benefícios financeiros estão classificados em dois tipos, de acordo com a composição familiar:

1) benefício básico de $R \$ 50$, destinado a famílias que se encontrem em situação de extrema pobreza, isto é, com renda mensal de até $\mathrm{R} \$$ 60 por pessoa, independentemente da composição familiar.

2) benefício variável, destinado a unidades familiares que se encontrem em situação de pobreza ou extrema pobreza e que tenham em sua composição: gestantes, nutrizes, crianças entre zero e 12 anos ou adolescentes até 15 anos.

O valor do benefício variável é de $\mathrm{R} \$ 15$, para cada criança ou adolescente de até 15 anos, no limite financeiro de até $\mathrm{R} \$ 45$, equivalente a três filhos por família.

Há ainda uma terceira modalidade, o chamado Benefício Variável de Caráter Extraordinário, concedido às famílias dos programas remanescentes (Bolsa Escola, Bolsa Alimentação, Cartão Alimentação e Auxílio-gás), cuja migração para o PBF implique perdas financeiras à família. $\mathrm{O}$ valor concedido é calculado caso a caso e possui prazo de prescrição, além do qual deixa de ser pago.

O Quadro 1 especifica os valores dos benefícios que as famílias integrantes do Programa podem receber: nistério da Saúde e levadas, periodicamente, aos postos de saúde para verificação de seu desenvolvimento e nutrição. As crianças e adolescentes até 16 anos completos devem freqüentar a escola e apresentar pelo menos $85 \%$ de freqüência nas aulas.

As condicionalidades têm por objetivo monitorar continuamente a população-alvo dos benefícios de modo a, caso seja necessário, levar a algum tipo de intervenção governamental. No caso do PBF, de acordo com Linhares (2005), as condições para a suspensão ou cancelamento dos benefícios concedidos em função do não cumprimento das condicionalidades não foram definidas em legislação. Aliás, ainda segundo Linhares, as condicionalidades desse programa ressaltam o dever dos diversos níveis de governo em garantir o direito de acesso pleno aos serviços educacionais e de saúde às famílias beneficiárias.

Comparado à proposta anterior (Lei 9.533/97), o PBF é mais abrangente e tem uma importância crescente, principalmente nos municípios menos desenvolvidos, mas ainda assim é um programa condicional.

No mesmo ano de sanção do PBF, 2004, a Presidência da República também sancionou o projeto de lei do senador Suplicy, Lei 10.835/04 que dispõe sobre o Programa Renda Básica de Cidadania.

\subsection{Renda básica de cidadania}

A lei que cria uma renda básica de cidadania (RBC) consiste no direito de todos os brasileiros residentes no país, além de estrangeiros que vivem há pelo menos cinco anos no Brasil, a uma renda mínima, não importando a sua condição socioeconômica. O pagamento do benefício deverá ser de igual valor para todos e suficiente para atender às despesas mínimas de cada pessoa com alimentação, educação e

\section{Quadro 1 - Valores dos benefícios}

\begin{tabular}{|c|c|c|c|c|}
\hline \multicolumn{2}{|c|}{ Critério de Elegibilidade } & \multirow{2}{*}{$\begin{array}{c}\text { Ocorrência de Crianças / } \\
\text { Adolescentes 0-15 anos, } \\
\text { Gestantes e Nutrizes }\end{array}$} & \multirow{2}{*}{$\begin{array}{l}\text { Quantidade e } \\
\text { Tipo de } \\
\text { Benefícios }\end{array}$} & \multirow{2}{*}{$\begin{array}{c}\text { Valores do } \\
\text { Benefício } \\
\text { (R\$) }\end{array}$} \\
\hline Situação das Famílias & $\begin{array}{c}\text { Renda } \\
\text { Mensal per capita }\end{array}$ & & & \\
\hline \multirow{3}{*}{ Situação de Pobreza } & de $\mathrm{R} \$ 60,01$ & 1 Membro & (1) Variável & 15 \\
\hline & $\mathrm{a}$ & 2 Membros & (2) Variável & 30 \\
\hline & $\mathrm{R} \$ 120$ & 3 ou + Membros & (3) Variável & 45 \\
\hline \multirow{4}{*}{$\begin{array}{c}\text { Situação de Extrema } \\
\text { Pobreza }\end{array}$} & \multirow{4}{*}{$\begin{array}{c}\text { até } \\
\mathrm{R} \$ 60\end{array}$} & Sem Ocorrência & Básico & 50 \\
\hline & & 1 Membro & Básico + (1) Variável & 65 \\
\hline & & 2 Membros & Básico + (2) Variável & 80 \\
\hline & & $3 \mathrm{ou}+$ Membros & Básico + (3) Variável & 95 \\
\hline
\end{tabular}

Fonte: Ministério do Desenvolvimento Social e Combate à Fome (BRASIL, 2006a).

A contrapartida para fazer jus ao recebimento do benefício do PBF é o cumprimento de compromissos por parte das famílias beneficiárias nas áreas de saúde, alimentação e educação. As crianças até 6 anos devem ser vacinadas, conforme o calendário do Mi- saúde, considerando para isso o grau de desenvolvimento do país e as suas possibilidades orçamentárias. O pagamento do benefício poderá ser feito em parcelas iguais e mensais. Trata-se ainda de benefício não tributável para efeito do imposto de renda. 
A implantação da lei deverá ser alcançada em etapas, a critério do Poder Executivo, priorizando-se as camadas mais necessitadas da população. Também fica a cargo da Presidência definir o valor do benefício, levando em consideração a Lei de Responsabilidade Fiscal. O Orçamento Geral da União de 2005 já deveria prever dotação suficiente para implementar a primeira etapa do projeto e, a partir do exercício financeiro de 2005 , os projetos de lei relativos aos planos plurianuais e às diretrizes orçamentárias deveriam especificar os cancelamentos e as transferências de despesas, bem como outras medidas julgadas necessárias à execução do programa.

O projeto tramitou cerca de um ano em cada uma das Casas Legislativas. No Senado teve como relator o senador Francelino Pereira (PFLMG), que ponderou a necessidade de implementação gradual do RBC, para estar de acordo com a Lei de Responsabilidade Fiscal. Na Câmara dos Deputados o processo deliberativo foi ainda mais tranqüilo. $\mathrm{O}$ relator da matéria foi o deputado Paulo Bernardo (PTPR) e nenhuma emenda foi apresentada.

Embora sancionada esta lei não teve a mesma repercussão que o Bolsa Família. Passou ao largo da grande mídia e dos discursos governamentais. Resta saber o porquê de tamanho silêncio.

\section{Considerações finais}

Os programas de renda mínima implementados no Brasil têm como mote a noção de que não é possível combater a exclusão econômica e social sem se levar em conta que é preciso dotar as pessoas de capacidades para obterem e cobrarem melhores condições de bem-estar. Esta capacitação viria através da educação. Por esta razão, os projetos de renda mínima que surgiram nos últimos anos vinculam a concessão do benefício à permanência das crianças na escola.

A justificativa para a vinculação do acesso ao benefício à matrícula e freqüência das crianças na escola é a seguinte: os segmentos sociais menos favorecidos têm dificuldade em manter seus filhos estudando, não tanto pelo custo financeiro, mas pela importância que os rendimentos ganhos pelas crianças e pelos adolescentes têm na composição da renda familiar. Ao ingressarem prematuramente no mercado de trabalho, a acumulação de capital humano, via sistema educativo, fica comprometida. Para romper com esse círculo vicioso é necessário que se dê algum tipo de compensação monetária para que os pais mantenham seus filhos estudando. A marginalidade econômica e social seria decorrência de deficiências na formação do capital humano e ao se dar condições para formação escolar aos jovens, estaríamos contribuindo para a eliminação dessa marginalidade (RAMOS, 1998).

Um aspecto problemático da Lei 9.533/97 referia-se à unidade implementadora do projeto: o município.Em que medida projetos dessa natureza não incentivariam um amplo fluxo migratório? Como possível solução, a exigência de um longo período de residência no município poderia resolver essa questão, mas ainda assim uma parcela significativa da população poderia ficar excluída.

Cabe ainda indagar, em que medida um projeto que exclui as famílias sem crianças (e aqui a referência pode ser tanto a Lei 9.533/97 quanto o Bolsa Família do governo Lula) cumpre suas metas quanto à eqüidade? Nestes termos, a adoção de um programa desta natureza parece ser insuficiente para o combate à pobreza e, mais ainda, para tornar as pessoas portadoras de uma liberdade real nos termos propostos por Van Parijs.

Os projetos aqui apresentados, a Lei 9.533/97, o Bolsa Família e o Renda Básica de Cidadania representam dois modelos de formulação de política social: a universalização e a focalização. Por que prevaleceu um modelo (no momento, o Bolsa Família) em detrimento do outro?

Uma forma de se enfrentar este questionamento pode assentar-se na discussão quanto aos critérios de justiça. Dois princípios, o da igualdade e o da eqüidade, podem ser vinculados aos dois modelos antes citados: o da universalização e o da focalização. Pelo princípio da igualdade adotaríamos políticas de perfil universalizante, atendendo ao preceito de que todos têm o direito a determinados serviços, pois todos os indivíduos são iguais. Não haveria, portanto, discriminações. Na focalização teríamos políticas direcionadas a uma população de beneficiários que se encontram impossibilitados de auferirem, por sua própria conta, determinados serviços que supram suas necessidades.

Como definir quais necessidades devem ser objeto de política pública? $\mathrm{Na}$ focalização há um elemento de arbitrariedade. No Bolsa Família foi estabelecido o critério renda. 
Outro aspecto importante é o de como definir a população-alvo. Um dos limites do princípio da eqüidade consiste justamente em estabelecer quem será o grupo de beneficiários. Como justificar que uma família com crianças e adolescentes até 16 anos, cuja renda familiar per capita é inferior a meio salário mínimo, é mais necessitada que outra com a mesma renda, porém composta por adolescentes maiores de 16 anos, desempregados e com um idoso que necessita de cuidados médicos?

O parágrafo precedente pode levar, num primeiro momento, à defesa de políticas universalizantes. Mas como adotar políticas dessa natureza em sociedades marcadas pela escassez de recursos? ${ }^{6}$ Diante de tal limitação voltamos à necessidade de definir quem tem direito ao acesso. De acordo com Medeiros (1999, p, 2), "[...] havendo diretrizes gerais para a alocação de recursos, as decisões utilizarão os mesmos princípios para todos os indivíduos. Se essas diretrizes não existirem, tais decisões serão discricionárias, ou seja, ficarão à critério de quem detém o poder de decidir caso a caso".

No Bolsa Família, o Decreto 5.749, de 11 de abril de 2006 "atualiza os valores referenciais para caracterização das situações de pobreza e extrema pobreza". Assim, qualquer governante de plantão pode alterar $\mathrm{o}$ acesso, redefinindo o valor mínimo a partir do qual uma família se habilitaria a participar do programa.

Aparentemente tais dilemas desaparecerão quando a Renda Básica de Cidadania estiver em plena vigência. A questão no momento é saber se de fato a lei que a institui será aplicada, ou se será apenas mais um caso de 'lei que pega e não de lei que não pega'. Quem viver verá.

\section{Referências}

BARROS, R.; HENRIQUES, R.; MENDONÇA, R. Desigualdade e pobreza no Brasil: retrato de uma estabi-lidade inaceitável. Dossiê Desigualdade. Revista Brasileira de Ciências Sociais, São Paulo, v. 15, n. 42, p. 123-142, 2000.

BRASIL. Ministério do Desenvolvimento Social e Combate à Fome. Serviços. Disponível em <www.mds.gov.br/> . Acesso em: set. 2006a.

Presidência da República. Lei 8.742, de 7 de dez. 1993. Dispõe sobre a organização da Assistência Social e dá outras providências. Disponível em <www.planalto.gov.br/ CCIVIL/leis/L8742.htm>. Acesso em: set2006b.

DRAIBE, S. O welfare state no Brasil: características e perspectivas. Ciências Sociais Hoje, Anuário da ANPOCS, n. 12, São Paulo: Editora Vértice, 1989.

.; Wilnês, H. Welfare state, crise e gestão da crise: um balanço da literatura internacional. Revista Brasileira de Ciências Sociais, n. 6, v. 3 p. 53-78, 1988.
GARGARELLA, R. El ingreso ciudadano como política igualitaria”. In: LO VUOLO, R. (Comp.). Contra la exclusión. La propuesta del ingreso ciudadano. Buenos Aires: CIEPP/Miño y Dávila Editores, 1995, p. 323-342.

LAVINAS, L. Combinando compensatório e redistributivo: o desafio das políticas sociais no Brasil. In: HENRIQUES, R. (Org.). Desigualdade e pobreza no Brasil, Rio de Janeiro: IPEA, 2000, p. 503-520.

; VARSANO, R. Programa de garantia de renda mínima e ação coordenada de combate à pobreza. In: LOBATO, A. L. M. (Org.). Garantia de renda: ensaios e propostas. Brasília: IPEA, 1998, p. 47-80.

LINHARES, F. Bolsa Família: um novo arranjo para os Programas de Transferência de Renda no Brasil. Dissertação (Mestrado em Política Social) - Universidade Federal Fluminense, Niterói, 2005.

MEDEIROS, M. Princípios de justiça na alocação de recursos em saúde. Rio de Janeiro: IPEA, 1999. (Série Texto para Discussão n. 687).

RAMOS, C. A. Programa de renda mínima garantida. In: LOBATO, A. L. M. (Org.). Garantia de renda: ensaios e propostas. Brasília: IPEA, 1998, p. 203-250.

RAWLS, J. Uma teoria da justiça. Lisboa: Editorial Presença, 1993.

O liberalismo político. São Paulo: Ática, 2000.

SCHWARZER, H. Impactos socioeconômicos do sistema de aposentadorias rurais no Brasil - Evidências empíricas de um estudo de caso no estado do Pará. Rio de Janeiro: IPEA, 2000. (Série Texto para Discussão n. 729).

VAN PARIJS, P. O que é uma sociedade justa? São Paulo: Ática, 1997.

Más allá de la solidaridad. Los fundamentos éticos del Estado de bienestar y su superación. In: LO VUOLO, R. (Comp.). Contra la exclusión. La propuesta del ingreso ciudadano. Buenos Aires: CIEPP/Miño y Dávila Editores, 1995 , p. 55-82.

Capitalismo de renda básica. Revista Lua Nova, São Paulo, n. 32, p. 69-91, 1994.

\section{Notas}

1 Não há, entre os analistas, o menor consenso quanto à chamada crise do welfare state. Para alguns não se trataria sequer de crise. A este respeito ver Draibe e Wilnês (1988). 
2 Diário da Câmara dos Deputados, 10.12.1996. Disponível em $<$ http://imagem.camara.gov.br/diarios.asp $>$.

3 Diário da Câmara dos Deputados de 05/12/97, loc. cit.

4 Loc. cit.

$5 \mathrm{O}$ texto das diversas leis expostas neste texto encontra-se disponível em: $<$ http://www.mds.gov.br/servicos/legislacao>.

6 Reconheço, evidentemente, mas não trago para a discussão, que a posição da economia brasileira no contexto internacional e as exigências impostas por organismos internacionais quanto ao superávit primário, reformas institucionais, divída pública, etc, são variáveis importantes para a questão da disponibilidade (ou não) de recursos para o financimento das políticas sociais. Alguns estudiosos chegam até mesmo a afirmar que o Brasil não enfrenta problemas de escassez de recursos, absoluta ou relativa, para combater a pobreza. Ver a este respeito Barros, Henriques eMendonça(2000).

\section{Simone Diniz}

Doutora em Ciência Política pela Universidade de São Paulo (USP)

Professora da Faculdade e Instituto Paulista de Ensino (FIPEN) e da Pontifícia Universidade Católica de São Paulo - PUC-SP

FIPEN, Rua Euclides da Cunha, 377

Osasco - São Paulo

CEP: 06016-030 